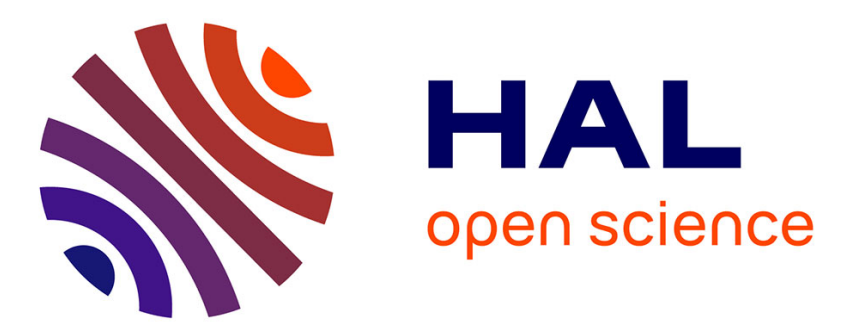

\title{
Electrical percolation and electromagnetic properties of polydimethylsiloxane composites filled with Ag nanoparticles of different sizes
}

Edita Palaimiene, Sebastien Schaefer, Jan Macutkevic, Juras Banys, Algirdas Selskis, Vanessa Fierro, Alain Celzard

\section{To cite this version:}

Edita Palaimiene, Sebastien Schaefer, Jan Macutkevic, Juras Banys, Algirdas Selskis, et al.. Electrical percolation and electromagnetic properties of polydimethylsiloxane composites filled with $\mathrm{Ag}$ nanoparticles of different sizes. Polymer Composites, 2020, 41 (11), pp.4750-4756. 10.1002/pc.25748 . hal-03041976

\section{HAL Id: hal-03041976 \\ https://hal.univ-lorraine.fr/hal-03041976}

Submitted on 20 Dec 2020

HAL is a multi-disciplinary open access archive for the deposit and dissemination of scientific research documents, whether they are published or not. The documents may come from teaching and research institutions in France or abroad, or from public or private research centers.
L'archive ouverte pluridisciplinaire HAL, est destinée au dépôt et à la diffusion de documents scientifiques de niveau recherche, publiés ou non, émanant des établissements d'enseignement et de recherche français ou étrangers, des laboratoires publics ou privés. 


\title{
Electrical percolation and electromagnetic properties of polydimethylsiloxane composites filled with Ag nanoparticles of different sizes
}

\author{
E. Palaimiene ${ }^{1}$, S. Schaefer ${ }^{2}$, J. Macutkevic ${ }^{1}$, J. Banys ${ }^{1}$, A. Selskis ${ }^{3}$, V. Fierro ${ }^{2}$, A. Celzard ${ }^{2}$ \\ ${ }^{1}$ Vilnius University, Sauletekio Ave. 3, Vilnius, Lithuania \\ ${ }^{2}$ Université de Lorraine, CNRS, IJL, 88000 Epinal, France \\ ${ }^{3}$ Center for Physical Science and Technology Sauletekio Ave. 3, Vilnius, Lithuania
}

\begin{abstract}
This paper deals with the dielectric/electrical properties of nanocomposites based on PDMS filled with Ag nanoparticles of different sizes. The measurements were carried out over a very broad range of frequencies $(20 \mathrm{~Hz}-40 \mathrm{GHz})$, and the results showed that the percolation threshold in the composites is close to $20 \mathrm{vol} \%$ and that it is almost independent of particle size. The observed critical exponent reasonably agrees with the theoretical values. Above the percolation threshold, the values of dielectric permittivity and electrical conductivity are quite high, $\varepsilon^{\prime} \approx 10^{7}$ and $\sigma \approx 0.1 \mathrm{~S} / \mathrm{cm}$ at room temperature and frequency of $129 \mathrm{~Hz}$. The dielectric permittivity of composites decreases strongly with frequency, especially in the microwave range, while the frequency behaviour of conductivity strongly depends on the concentration of nanoparticles. Nevertheless, the electrical conductivity and the dielectric permittivity remain high at microwaves $(0.1 \mathrm{~S} / \mathrm{m}$ and 10 , respectively), for composites with $\mathrm{Ag}$ nanoparticles of size $80-100 \mathrm{~nm}$ at a concentration of 30 vol\%.
\end{abstract}

\section{Introduction}

Electronics, automotive, laser and other industries constantly require new materials with a variety of special properties (such as high dielectric permeability, low losses, pronounced nonlinear effects, etc.). Nowadays, much attention is paid to the search for new polymeric composite materials, for applications in flexible electronic devices [1]. In the consumer technology market, there is a need for the printed electronic market to manufacture devices such as thin-film transistors, sensors, radio frequency components and devices, transparent electrodes, electronic films, flexible sensors for personal healthcare and more [2]. The production and capabilities of these devices are topical issues in medicine, industry, and telecommunications. So far, metallic nanoparticles with a polymeric matrix have been studied and applied for these purposes [3]. Polydimethylsiloxane (PDMS) is the most widely used silicon-based organic polymer [4]. The multiple valuable features of PDMS, such as flexibility and thermal stability, make it an excellent matrix material for composites [5]. It has been shown that, by changing the size of the conductive fillers in the PDMS matrix from micro to nano, the concentration threshold necessary for the onset of conductivity is lowered [5]. To exploit the potential of application of Ag nanoparticles (AgNPs) in optical limiting materials, it is important to develop nonlinear polymeric materials loaded with AgNPs because of their relatively low cost, their narrow dispersion in the refraction index, their practically endless possibilities of structure modification and their good processability [6]. One possible composite material is silver-loaded polydimethylsiloxane (Ag/PDMS) [7-8]. Electrical studies of composites filled with Ag 
nanoparticles have shown that the percolation threshold can be 10-30 vol.\%, depending on the type of polymer matrix and the technology used to prepare the composites [9-11].

The aim of this paper is to investigate the electromagnetic properties of Ag/PDMS composites with different sizes of Ag particles in wide frequency and temperature ranges.

\section{Experimental}

Ag nanoparticles (AgNPs) of different particle sizes (30-50 nm, 50-80 nm; 80-100 nm) were purchased from US Research Nanomaterials, Inc (USA), while the PDMS matrix was purchased from Farnell (France) under the reference Sylgard 184 Silicone Elastomer (Dow Corning®). Three series of composites were prepared, each based on a specific size of Ag nanoparticles, at AgNPs fractions close to $0,0.5,1,2,5,10,20$ and 30 vol.\%. Such volumes fractions were obtained by weighing amounts of Ag-NPs calculated from knowledge of the densities of silver $\left(10.49 \mathrm{~g} / \mathrm{cm}^{3}\right)$ and of PDMS after curing $\left(1.04 \mathrm{~g} / \mathrm{cm}^{3}\right)$.

Prior to any synthesis, the PDMS was degassed under reduced pressure (4 $000 \mathrm{~Pa}, 30 \mathrm{~min}$ ) at room temperature. For each composite, the corresponding amount of AgNPs was dispersed in isopropanol (IPA) and under inert atmosphere $\left(\mathrm{N}_{2}\right)$ in order to prevent any oxidation of the silver. The IPA solution containing the AgNPs was then sonicated for $3 \mathrm{~h}$ in an ultrasonic bath (VWR USC $1200 \mathrm{TH}, 600 \mathrm{~W}$ ), and for $5 \mathrm{~min}$ using a sonotrode (VWR DIGITAL, 450W, with a $13 \mathrm{~mm}$ diameter probe) at $20 \%$ of its maximum power. The IPA solution was then poured onto the corresponding amount of PDMS and was then sonicated using the same procedure. In order to evaporate the IPA, the IPA/AgNPs/PDMS blend thus obtained was placed overnight in a ventilated oven at $60^{\circ} \mathrm{C}$. The resultant PDMS/AgNPs paste was sonicated (ultrasonic bath) once more for 1.5h. The required amount of curing agent specified by the supplier was then added. The resultant mixture was then gently stirred by hand for $10 \mathrm{~min}$. In order to remove air bubbles possibly trapped during this step, the final mixture was degassed under reduced pressure (4000 $\mathrm{Pa}, 2 \mathrm{~min}$ ). Depending on the viscosity of the final mixes, the composites were cast or manually pressed in moulds before curing. Uncured composites containing $0,0.5,1,2,5$ and $10 \mathrm{vol} \%$ of $\mathrm{Ag}$ were poured in coin-size moulds, while uncured composites containing 20 and $30 \mathrm{vol} \%$ were pressed before or during the curing step. The composites were finally cured for $2-3 \mathrm{~h}$ at $90^{\circ} \mathrm{C}$ in a ventilated oven.

Scanning electron microscopy (SEM) images were obtained with a JSM 6460 LV electron microscope. Broadband measurements were performed using several techniques. At low frequencies $(20 \mathrm{~Hz}-1 \mathrm{MHz})$, the complex dielectric permittivity was obtained from the complex capacitance, which was measured by a precision HP4824 LCR meter. At frequencies from $1 \mathrm{MHz}$ to $1 \mathrm{GHz}$, the complex dielectric permittivity was calculated from the complex reflection coefficient, which was measured by an Agilent 8714ET vector network analyser, using a sample placed in a coaxial line. In the microwave frequency range, from $8 \mathrm{GHz}$ to $50 \mathrm{GHz}$, the reflectance and transmission of a thin dielectric rod placed inside a waveguide was studied. For these measurements, a homemade waveguide spectrometer was used [2]. The typical value for the rod diameter was several hundred micrometres. In the frequency range from $1 \mathrm{MHz}$ to $53 \mathrm{GHz}$, the measurement accuracy was $\sim 10 \%$. At low frequencies $(20 \mathrm{~Hz}-1 \mathrm{MHz})$, the measurements were also performed in the temperature range of $100-500 \mathrm{~K}$. Silver paste was used to make electric contacts with the samples. The real part $\sigma^{\prime}$ of the complex electrical conductivity was calculated as $\sigma^{\prime}=\omega \varepsilon_{0} \varepsilon^{\prime \prime}$, where $\omega$ is the angular frequency, $\varepsilon_{0}$ is the permittivity of vacuum, and $\varepsilon "$ is the imaginary part of the complex effective permittivity. 


\section{Results and discussion}

SEM images of PDMS-based composite materials filled with AgNPs of different sizes are presented in Fig. 1. It can be concluded that Ag nanoparticles are always well dispersed because all zones observed on various samples prepared at different volume fractions and particle size all look strictly identical.

The concentration dependences of both dielectric permittivity and electrical conductivity for different sizes of AgNPs at $129 \mathrm{~Hz}$ and room temperature are presented in Fig. 2. The values of electrical conductivity and dielectric permittivity were selected at $129 \mathrm{~Hz}$ frequency, since at lower frequencies the concentration dependence is more pronounced. For concentrations not higher than $15 \mathrm{vol} . \%$, the values of dielectric permittivity and electrical conductivity are rather low (about 10 and $1 \mathrm{nS} / \mathrm{m}$, respectively) and are independent of the AgNPs size. An abrupt increase in dielectric permittivity and electrical conductivity occurs near a volume concentration of NPs of $20 \%$, regardless of the particle size, indicating the onset of electrical percolation. According to classical percolation theory, the dependencies on the filler concentration of both dielectric permittivity $\varepsilon$ ' and electrical conductivity $\sigma^{\prime}$ above the percolation threshold, respectively, follow power laws with different critical exponents $g$ and $t$ [3-5]:

$$
\begin{aligned}
& \varepsilon^{\prime}=\varepsilon_{p}\left(f_{\mathrm{c}}-f\right)^{-g} \\
& \sigma_{\mathrm{DC}}{ }^{\prime}=\sigma_{p}\left(f-f_{c}\right)^{t}
\end{aligned}
$$

where $f$ and $f_{c}$ are the volume fraction and the critical volume fraction (percolation threshold) of filler, respectively, and $\varepsilon_{p}$ and $\sigma_{p}$ are the permittivity and the conductivity of the filler, respectively. The parameters obtained are gathered in Table $\mathbf{I}$.

At concentrations close to the percolation threshold, the percolation theory predicts an exponent value close to 2 in any three-dimensional medium [6]. The results of the fits show that the percolation threshold in the composites is close to $20 \mathrm{vol} . \%$ and that it is almost independent of the particle size. Above the percolation threshold, the values of dielectric permittivity and electrical conductivity are very high (higher than $10^{7}$, and higher than $0.1 \mathrm{mS} / \mathrm{m}$, respectively) and are almost independent of the size of the AgNPs.

The frequency dependencies of the dielectric permittivity and electrical conductivity for Ag/PDMS composites with different sizes of Ag particles are presented in Fig. 3.

Below room temperature, the DC electrical conductivity increases when the temperature decreases, and reaches a maximum around $180 \mathrm{~K}$, which is close to the glass transition temperature of the pure PDMS matrix (150 K) (Fig. 4) [7]. The behaviour can be explained by a rapid shrinkage of the PDMS matrix upon cooling down to the glass transition temperature, and consequently by the increase in the tunnelling conductivity between Ag particles during cooling. Below $180 \mathrm{~K}$, the DC electrical conductivity decreases upon cooling. In the temperature ranges $280-220 \mathrm{~K}$ and $160-$ $120 \mathrm{~K}$, the electrical conductivity in the frequency range of $20 \mathrm{~Hz}-1 \mathrm{MHz}$ coincides with DC conductivity, but in the temperature range $160-220 \mathrm{~K}$, the electrical conductivity exhibits a marked frequency dependence, i.e., it decreases with frequency. This effect can be related to spatial redistributions of $\mathrm{Ag}$ nanoparticles within the PDMS matrix close to the glass transition temperature. For example, AgNPs might be expelled from PDMS areas gradually becoming glassy towards areas that are still rubbery and within which clusters of AgNPs might be formed. For the electrical conductivity at higher frequencies is important the electrical transport insidethe smaller conductive clusters of nanoparticles. Thus, decreasing the amount of small conductive clusters can effectively decrease the electrical conductivity at higher frequencies.

The conductivity spectra of PDMS composites with AgNPs of size 80-100 nm are shown in Fig. 5. 
The conductivity spectra are dependent on temperature, therefore, $\sigma(\omega)$ has been fitted with $\sigma=\sigma_{\mathrm{DC}}$ $+\mathrm{A} \omega^{\mathrm{s}}[8]$, where $\sigma_{\mathrm{DC}}$ and $\mathrm{A} \omega^{\mathrm{s}}$ are $\mathrm{DC}$ and $\mathrm{AC}$ conductivities, respectively. The temperature dependences of DC conductivity are presented in Fig. 6. The DC conductivity data at temperatures below $180 \mathrm{~K}$ are well fitted by the fluctuation-induced tunnelling (FIT) model [9]:

$$
\begin{aligned}
& \sigma_{D C}=\sigma_{0} \exp \left[-T_{1} /\left(T+T_{0}\right)\right], \\
& T_{1}=\omega A \varepsilon_{0}^{2} / 8 \pi k, \\
& T_{0}=A \varepsilon_{0}^{2} / 4 \pi^{2} \chi k,
\end{aligned}
$$

where $T$ is the temperature, $\omega$ is the width of the tunnelling gap, $A$ is the area of the capacitor formed by the tunnel junction, $k$ is the Boltzmann constant, $\varepsilon_{0}=4 V_{0} / \mathrm{ew}$ (where $V_{0}$ is the potential barrier height and $e$ is the electron charge) and $\chi=\left(2 m V_{0} / h^{2}\right)^{1 / 2}$ (where $m$ is the electron mass and $h$ is the Planck constant). The values obtained for $T_{1}$ and $T_{0}$ are listed in Table II. The $T_{1} / T_{0}$ ratio decreases with the concentration of $\mathrm{Ag}$, but it does not clearly depend on the size of Ag particles. This can be explained by the fact that from Eqs. (3-5), it follows that $T_{1} / T_{0}$ is proportional to the gap width $w$, which is approximately proportional to $\mathrm{p}^{1 / 3}$ (where $\mathrm{p}$ is AgNPs concentration) [10].

\section{Conclusion}

Broadband investigations of PDMS composites filled with AgNPs of different sizes indicates that the percolation threshold in these composites is close to $20 \mathrm{vol} \%$, and that it is almost independent of the particle size due to the uniform and homogeneous distribution of nanoparticles in the polymer matrix in contrast to results presented for composites with gold nanoparticles. The observed critical exponents reasonably agrees with the theoretical values. Above the percolation threshold, the values of dielectric permittivity and electrical conductivity are quite high, $\varepsilon^{\prime} \approx 10^{7}$ and $\sigma \approx 0.1 \mathrm{~S} / \mathrm{cm}$, respectively, at room temperature and frequency of $129 \mathrm{~Hz}$. The dielectric permittivity of the composites strongly decreases with frequency, especially at microwaves, while the frequency behaviour of the conductivity strongly depends on the concentration of nanoparticles. Nevertheless, both the electrical conductivity and dielectric permittivity remain high at microwaves $(0.1 \mathrm{~S} / \mathrm{m}$ and 10, respectively, for composites with Ag nanoparticles of size $80-100 \mathrm{~nm}$ at a concentration of 30 vol.\%). 


\section{References}

[1] M. Kaltebrubrunner, T. Sekitam, J. Reeder, T. Yokota, K. Kuribara, T. Tokuhara, M. Drack, R. Schwodiauer, I. Graz, S. Bauer-Gogonea, S. Bauer, T. Someya, Nature 499, 458 (2013).

[2] W. E. Frazier, Journal of Materials Engineering and Performance 23, 1917 (2014).

[3] J. Ozhikandathil, S. Badilescu, M. Packirisamy, Proc. SPIE 8007, Photonics North 2011, 800707 (2011)

[4] S. H. Cho, H. M. Anderson, S. R. White, N. R. Sottos, P. V. Braun, Advanced Materials 18, 997 (2006).

[5] X. Niu, S. Peng, L. Liu, W. Wen and P. Sheng, Advanced Materials 19, 2682(2007).

[6] T. Kokubo, H. M. Kim, M. Kawashita, Biomaterials 2003, 24,2161.

[7] J. H. Kong, N. S. Jang, S. H. Kim, J. M. Kim, Carbon 2014,77, 199.

[8] J. R. Huang, X. X. Yang, J. T. Liu, S. C. Her, J. Q. Guo, J. F.Gu, L. H. Guan, Nanotechnology 2020, 31, 335504.

[9]J.S.Li, Y.Z.Xie, W.B.Lu, T.W.Chou, Carbon 2018,129, 76.

[10] I. You, M. Kong, U. Jeong, Acc. Chem. Res. 2019, 52, 63.

[11] Y. Chen, Y. Araki, J. Doyle, A. Strevens, O. Ito, W. J. Blau,Chem. Mater. 2005, 17, 1661.

[12] Z. Wang, J. Ren, R. Liu, X. Sun, D. Huang, W. Xu, J. Jiang,K. Ma, Y. Liu, Compos.PartA:Appl.Sci.2020, 136,105957.

[13] K. H. Jung, J. Kim, B. G. Park, C. S. Lee, H. J. Sung, S. B. Jung,J. Alloys Compd. 2018, 748, 898.

[14] A. Larmagnac, S. Eggenberger, H. Janossy, J. Voros, Sci. Rep.2014, 4 , 7254.

[15] M. Jouni, A. Boudeni, G. Boiteux, V. Massardier, B. Garnier,A. Serhei, Polym. Compos. 2013, 34,778 .

[16] S. Aramesh, A. Doostmohammadi, P. Rezai, Polym. Compos.2019,40, 4093.

[17] M. Ekrem, N. Ataberk, A. Avci, A. Akdemir, J. Adhes. Sci.Technol. 2017, 31, 699.

[18] F. Zhang, G. Wang, C. Wang, C. Tang, T. Sun, X. Yu, Appl.Phys. Lett. 2018, 113, 253105.

[19] J. Grigas, Microwave Dielectric Spectroscopy of Ferroelectrics and Related Materials, Gordon and Breach Science, Amster-dam, the Netherlands 1996.

[20] J. Macutkevic, P. Kuzhir, D. Seliuta, G. Valusis, J. Banys, A.Paddubskaya, D. Bychanok, G. Slepyan, S. Maksimenko, V.Kuznetsov, S. Moseenkov, O. Shenderova, A. Mayer, P.Lambin, Diamond Relat. Mater. 2010, 19, 91.

[21] H. M. Kim, K. Kim, C. Y. Lee, J. Joo, S. J. Cho, H. S. Yoon,D. A. Pejakovic, J. W. Yoo, A. J. W. Yoo, A. J. Epstein, Appl.Phys. Lett. 2004, 84, 589.

[22] (a) L. Wang, Z. M. Dang, Appl. Phys. Lett. 2005, 87, 042903.(b) M. J. Jiang, L. M. Dang, H. P. Xu, Appl. Phys. Lett. 2007, 90,042914.

[23] D. J. Bergman, Phys. Rev. Lett. 1980, 44, 1285. 
[24] C. W. Nan, Prog. Mater. Sci. 1993, 37,1.

[25] J. Wu, D. S. Mclachan, Phys. Rev. B 1997, 56, 1236.

[26] S. Sagar, N. Iqbal, N. Maqsood, J. Phys.: Conf. Ser. 2013, 439,012024.

[27] I. Balberg, Phys. Rev. B 1986, 33, 3618.

[28] A. Celzard, E. McRae, C. Deleuze, M. Dufort, C. Furdin, J. F.Mareche, Phys. Rev. B 1996, 53 , 6209.

[29] J. Macutkevic, P. Kuzhir, A. Paddubskaya, S. Maksimenko, J.Banys, A. Celzard, V. Fierro, S. Bistarelli, A. Cataldo, F.Micciulla, S. Bellucci, J. Appl. Phys. 2013, 114, 033707.

[30] J. Macutkevic , I. Kranauskaite, J. Banys , S. Moseenkov, V.Kuznetsov, O. Shenderova, J. Appl. Phys. 2014, 115,213702.

[31] D. Almond, G. K. Duncan, A. R. West, Solid State Ion. 1983,8, 159.

[32] A. Kheirandish, N. S. Javan, H. Mohammadzadeh, Sci. Rep.2020, 10, 6517.

[33] A. Plyushch, J. Macutkevic, S. Svirskas, J. Banys, V.Plausinaitiene, D. Bychanok, S. A. Maksimenko, A. Selskis, A.Sokal, K. N. Lapko, P. P. Kuzhir, Appl. Phys. Lett. 2019, 114,183105.

[34] A. Plyushch, J. Macutkevic, P. Kuzhir, A. Sokal, K. Lapko, A.Selskis, J. Banys, Appl. Sci. 2019, 9, 4388.

[35] P. Sheng, E. K. Sichel, J. I. Gittleman, Phys. Rev. Lett. 1978, 40,1197.

[36] T. A. Ezquerra, M. Kulesza, F. J. Balta-Galleja, Synth. Met.1991, 41-43, 915. 

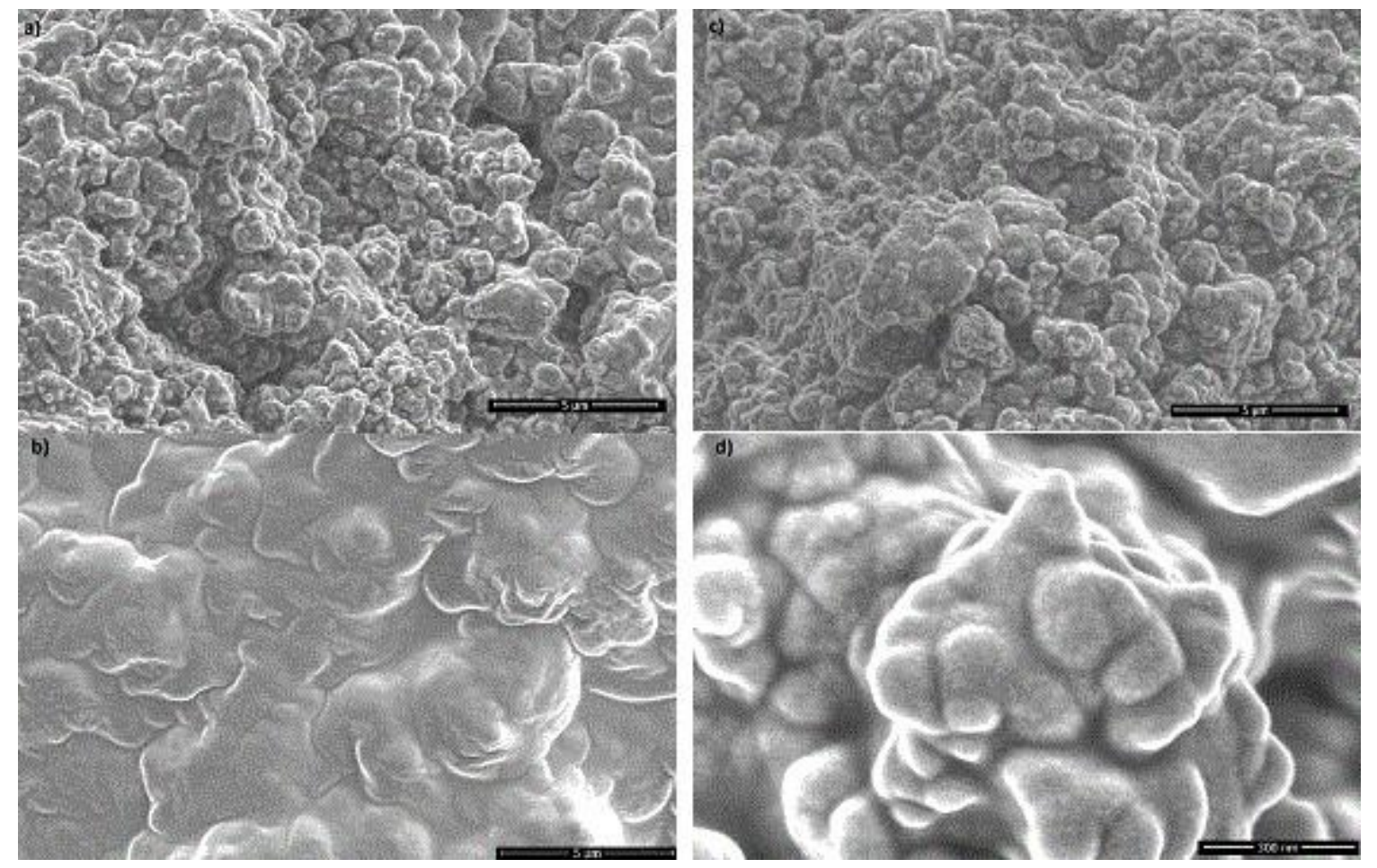

FIG. 1. SEM images of PDMS composite materials filled with AgNPs of different sizes and at different volume fractions: (a) 28.54 vol. \% for 30-50 nm AgNPs; (b) 19.23 vol. \% of 80-100 nm AgNPs; (c) 30.22 vol. \% of 80-100 nm AgNPs; (d) 30.22 vol. \% of 80-100 nm AgNPs.

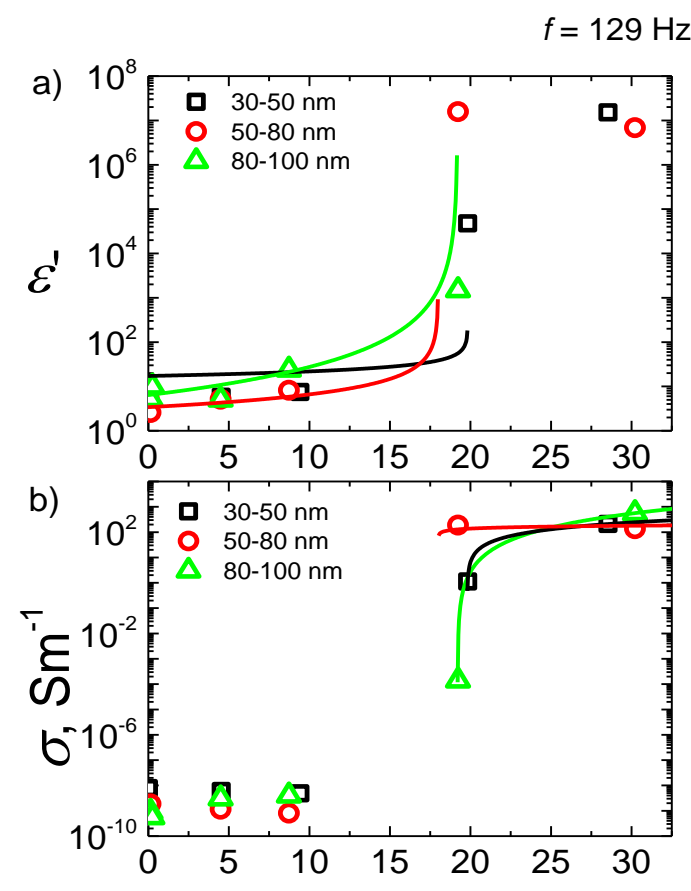

Ag Nanoparticles concentration (vol\%)

FIG. 2. Dielectric permittivity (a) and electrical conductivity (b) of Ag/PDMS composites vs Ag concentration and for different particle sizes, at frequency $129 \mathrm{~Hz}$ and room temperature. 
TABLE I. Percolation threshold, $f c$, and corresponding critical exponents of the permittivity, $g$, and of the electrical conductivity, below and above the threshold.

\begin{tabular}{|lcll|}
\hline Average size of Ag aggregates $(\mathrm{nm})$ & $f \mathrm{c}$ (vol. \%) & $\boldsymbol{g}$ & $\boldsymbol{t}$ \\
\hline $30-50$ & 18 & 0.81 & 2.55 \\
\hline $50-80$ & 18 & 0.81 & 0.14 \\
\hline $80-100$ & 19.2 & 1.98 & 2.03 \\
\hline
\end{tabular}

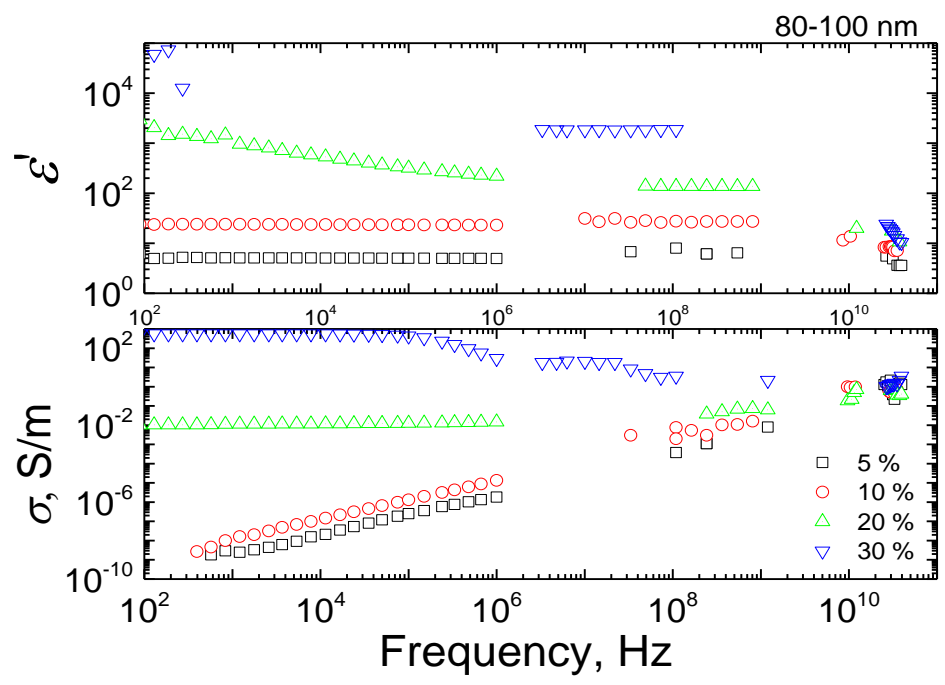

FIG. 3. Frequency spectra of dielectric permittivity and electrical conductivity for Ag/PDMS composites with AgNPs of average size $80-100 \mathrm{~nm}$ at room temperature.

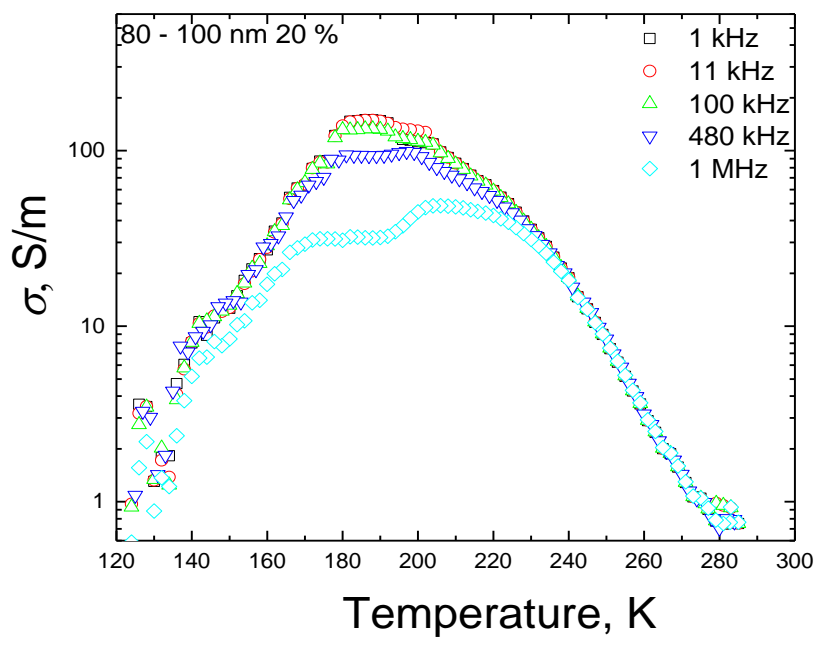


FIG. 4. Temperature dependence of the electrical conductivity of Ag/PDMS composites with 20 vol.\% of 80 $100 \mathrm{~nm}$ AgNPs, at different frequencies.

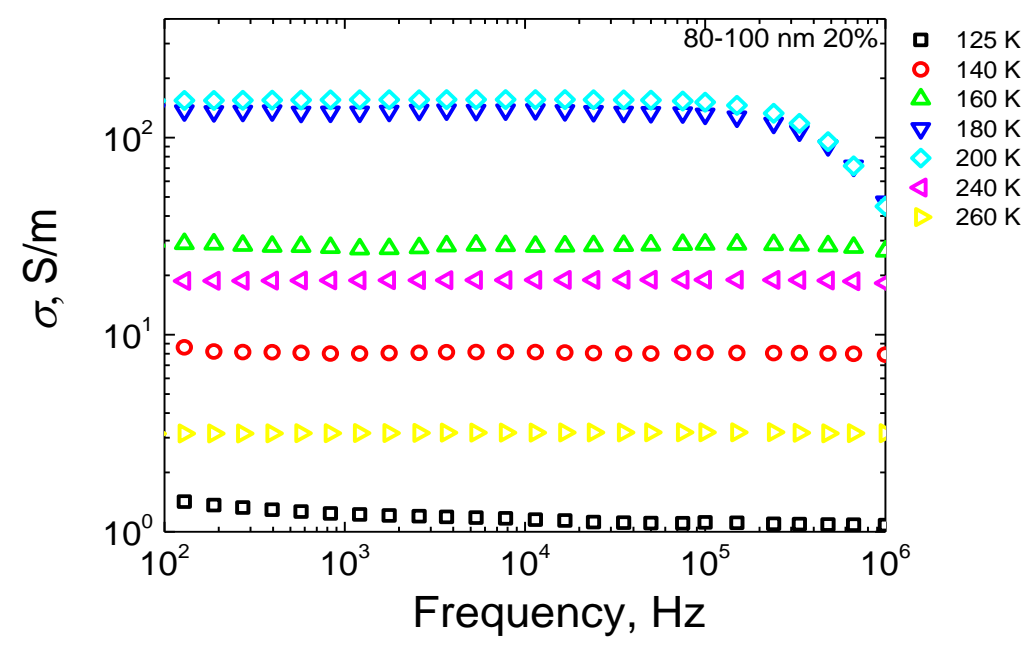

FIG. 5. Frequency dependence of the electrical conductivity of Ag/PDMS composites with 20 vol.\% of 80 $100 \mathrm{~nm}$ AgNPs, at different temperatures.

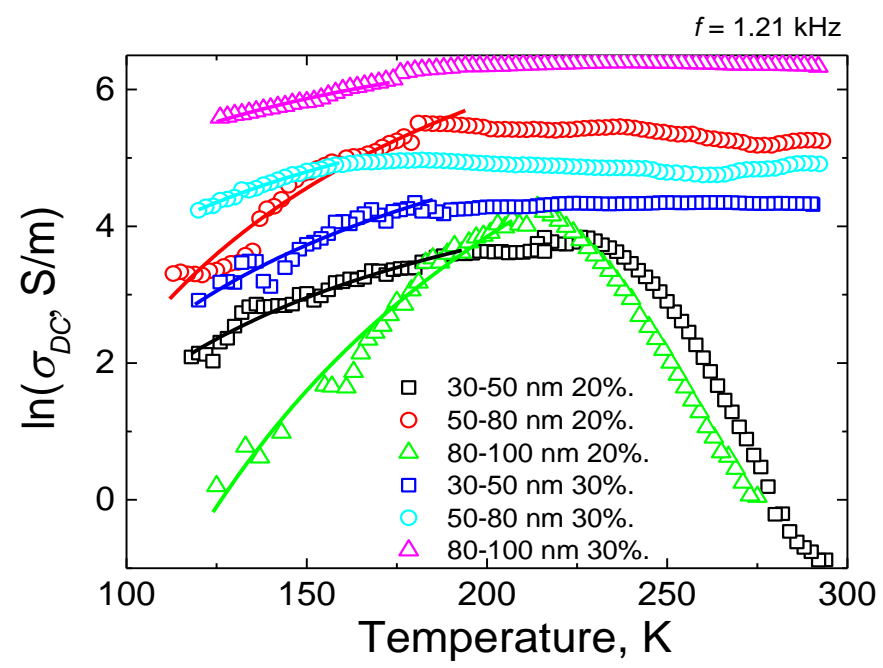

FIG. 6. Temperature dependence of the DC conductivity at frequency $1.21 \mathrm{kHz}$ of Ag/PDMS composites, to which the tunnelling law (Eq. (3)) has been fitted. 
TABLE II. Tunnelling model fit parameters for DC conductivity at low temperature.

\begin{tabular}{|c|c|c|c|c|c|}
\hline $\begin{array}{l}\text { Approximate concentration } \\
\text { and size of AgNPs }\end{array}$ & $\sigma_{\mathrm{DC} 0}, \mathrm{mS} / \mathrm{m}$ & $T_{0}, \mathrm{~K}$ & $T_{1}, \mathrm{~K}$ & $\begin{array}{l}\text { Real concentration, } \\
\text { vol. \% }\end{array}$ & $T_{1} / T_{0}$ \\
\hline \multicolumn{6}{|l|}{$20 \%$} \\
\hline $30-50 \mathrm{~nm}$ & 500.49 & 9.76 & 520.79 & 19.83 & 53.34 \\
\hline $50-80 \mathrm{~nm}$ & 19970.27 & 13.36 & 872.85 & 18.08 & 65.35 \\
\hline $80-100 \mathrm{~nm}$ & 109245.18 & 22.31 & 1723.77 & 19.23 & 77.28 \\
\hline \multicolumn{6}{|l|}{$30 \%$} \\
\hline $30-50 \mathrm{~nm}$ & 1911.45 & 17.42 & 641.01 & 28.54 & 36.80 \\
\hline $50-80 \mathrm{~nm}$ & 1655.43 & 21.01 & 447.18 & 29.57 & 21.23 \\
\hline $80-100 \mathrm{~nm}$ & 2608.55 & 23.01 & 346.02 & 30.22 & 15.04 \\
\hline
\end{tabular}

